\section{Commentary: Coronary revascularization in younger patients: Lessons from real-world practice}

\author{
Madeline L. Fryer, MMSc, ${ }^{\mathrm{a}}$ and \\ Leora B. Balsam, MD
}

The pendulum continues to swing toward surgical revascularization rather than percutaneous coronary intervention (PCI) for multivessel coronary artery disease (CAD) in a new study from the Journal. ${ }^{1}$ One of the challenges in the field of coronary revascularization is navigating a morass of evidence in which apples are often compared with oranges. Although there have been several high-quality randomized controlled clinical trials that guide heart teams today, such as FREEDOM (Future Revascularization Evaluation in Patients with Diabetes Mellitus: Optimal Management of Multivessel Disease) ${ }^{2}$ and SYNTAX (Synergy Between Percutaneous Coronary Intervention with TAXUS and Cardiac Surgery), ${ }^{3}$ trial enrollment criteria by definition exclude some individuals. For this reason, trial conclusions cannot be generalized to patients with characteristics that were not adequately represented, either due to exclusion or under-representation. Some common areas of underrepresentation or exclusion are female sex, low ejection fraction, and younger age. A second challenge: even wellintentioned randomized controlled trials can be flawed. Just this year, newly revised European guidelines that supported PCI in low- or intermediate-complexity left main disease were recanted due to major concerns with trial design in the EXCEL (Evaluation of XIENCE versus Coronary After Bypass Surgery for Effectiveness of Left

\footnotetext{
From the ${ }^{\mathrm{a}}$ University of Massachusetts Medical School; and ${ }^{\mathrm{b}}$ Division of Cardiac Surgery, UMass Memorial Medical Center, Worcester, Mass.

Disclosures: The authors reported no conflicts of interest.

The Journal policy requires editors and reviewers to disclose conflicts of interest and to decline handling or reviewing manuscripts for which they may have a conflict of interest. The editors and reviewers of this article have no conflicts of interest.

Received for publication April 12, 2020; revisions received April 12, 2020; accepted for publication April 13, 2020; available ahead of print May 4, 2020.

Address for reprints: Leora B. Balsam, MD, Division of Cardiac Surgery, UMass Memorial Medical Center, University Campus, 55 Lake Ave North, Worcester, MA 01655 (E-mail: leora.balsam@umassmemorial.org).

J Thorac Cardiovasc Surg 2022;163:659-60

$0022-5223 / \$ 36.00$

Copyright (c) 2020 by The American Association for Thoracic Surgery

https://doi.org/10.1016/j.jtcvs.2020.04.106
}

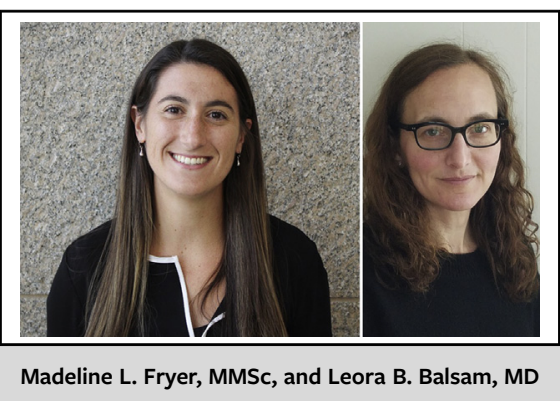

\section{CENTRAL MESSAGE \\ An observational study reaffirms the long-term survival benefit of CABG over PCI for multivessel CAD, focusing specifically on younger patients.}

Main Revascularization) $)^{4}$ trial. And a third challenge: where high-quality randomized controlled trials do not exist, can meaningful practice guidelines be gained from observational studies? A recent publication in JAMA Cardiology compared outcomes of PCI and coronary artery bypass grafting (CABG) in patients with low ejection fraction using propensity score matching techniques. ${ }^{5}$ Can their conclusions convincingly inform our practice decisions, or will limitations of study design prevent this?

In this issue of the Journal, ${ }^{1}$ the Northern New England Cardiovascular Study Group (NNECDSG) draws focus on the optimal revascularization strategy for younger patients $(<60$ years old) with severe multivessel CAD. The NNECDSG is a regional consortium founded in 1987 that maintains a registry of patients undergoing cardiac procedures in Maine, New Hampshire, and Vermont. The authors leverage on this large dataset to better understand the characteristics and outcomes of young patients undergoing PCI or CABG in their real-world practice setting. As a generalization, heart teams have often favored surgical revascularization in younger patients with severe multivessel coronary artery disease due to anticipated durability and survival benefit; however, these authors emphasize that existing trial data has been sparse in this age group.

The authors compare adjusted outcomes between PCI and CABG using propensity score methods and inverse probability weighting to redistribute known confounders. After excluding patients with single-vessel disease, they compare a cohort of 1945 patients undergoing CABG and 2938 patients undergoing PCI. CABG was associated with better 10-year survival compared with PCI, with 
significant differences in the late (rather than early) phase after revascularization. This benefit was noted in patients with 2-vessel disease with any involvement of the left anterior descending (LAD) and patients with 3-vessel disease. Need for repeat revascularization was more common in the PCI cohort, and time to reintervention was also shorter for the PCI cohort. Overall, these findings from the NNECDSG are consistent with previous observations from the randomized SYNTAX trial, which showed both improved survival and freedom from repeat revascularization at 5 years of follow-up for CABG compared with PCI in triple-vessel disease. ${ }^{6}$ Unlike SYNTAX, however, the NNECDSG did not collect detailed information about coronary anatomy, such as SYNTAX score. This type of information would help us understand the NNECDSG's results in the context of previous studies.

The CRAGS (Coronary aRtery disease in young adultS) study $^{7}$ is another multicenter, nonrandomized retrospective analysis of younger $(\leq 50$ years old) patients undergoing CABG or PCI for CAD. In this European study, patients who underwent PCI and CABG had similar short-term outcomes. Five years postintervention, all-cause mortality was similar after propensity score adjustment, but patients who underwent $\mathrm{CABG}$ had significantly reduced major adverse cardiac and cerebrovascular events, including myocardial infarction and repeat revascularization. This analysis differs from NNECDSG's in important ways. All-comers in the CRAGS registry were analyzed, including patients with ST-elevation myocardial infarction (37\%), single-vessel CAD $(51 \%)$, left main stenosis $(7 \%)$, and previous PCI $(8 \%)$. These patients were all excluded in the final NNECDSG analysis.
The NNECDSG study incrementally adds to our knowledge of how younger patients with multivessel CAD are being treated in the real world. For patients with single-vessel CAD or 2-vessel disease without proximal LAD lesions, PCI was predominant. For those with 2-vessel disease with proximal LAD lesions and 3-vessel disease, CABG was more commonly performed. When trying to transform apples to oranges with fancy statistical techniques, the longterm outlook favors CABG in multivessel disease rather than PCI.

\section{References}

1. Robich MP, Leavitt BJ, Ryan TJ, Westbrook BM, Malenka DJ, Gelb DJ, et al. Comparative effectiveness of revascularization strategies for early coronary artery disease: a multi-center analysis. J Thorac Cardiovasc Surg. 2022;163:645-56.e2.

2. Farkouh ME, Domanski M, Sleeper LA, Siami FS, Dangas G, Mack M, et al. Strategies for multivessel revascularization in patients with diabetes. $N$ Engl J Med. 2012;367:2375-84

3. Serruys PW, Morice MC, Kappetein AP, Colombo A, Holmes DR, Mack MJ, et al. Percutaneous coronary intervention versus coronary-artery bypass grafting for severe coronary artery disease. N Engl J Med. 2009;360:961-72.

4. Stone GW, Kappetein AP, Sabik JF, Pocock SJ, Morice MC, Puskas P, et al. Fiveyear outcomes after PCI or CABG for left main coronary disease. $N$ Engl J Med. 2019:381:1820-30

5. Sun LY, Gaudino M, Chen RJ, Eddeen AB, Ruel M. Long-term outcomes in patients with severely reduced left ventricular ejection fraction undergoing percutaneous coronary intervention vs coronary artery bypass grafting. JAMA Cardiol. April 8, 2020 [Epub ahead of print].

6. Mohr FW, Morice MC, Kappetein AP, Feldman TE, Stahle E, Colombo A, et al. Coronary artery bypass graft surgery versus percutaneous coronary intervention in patients with threevessel disease and left main coronary disease: 5-year follow-up of the randomised, clinical SYNTAX trial. Lancet. 2013; 381:629-38.

7. Biancari F, Gudbjartsson T, Heikkinen J, Antilla V, Makikallio T, Jeppsson A, et al. Comparison of 30-day and 5-year outcomes of percutaneous coronary intervention versus coronary artery bypass grafting in patients aged $\leq 50$ years (the Coronary aRtery diseAse in younG adultS Study). Am J Cardiol. 2014; 114:198-205. 